\title{
Cerámica artística en los espacios públicos de la ciudad de Zaragoza
}

\author{
Artistic ceramics in public spaces \\ in the city of Zaragoza \\ Sonia Arilla SATUÉ \\ Universidad de Zaragoza \\ soniasatue@gmail.com
}

Recibido: $19 / 01 / 2016$

Aceptado: 18/03/2016

\section{Resumen}

Este artículo analiza la evolución del legado cultural cerámico en la ciudad de Zaragoza desde la década de los cuarenta del siglo XX hasta comienzos del siglo XXI. A través de un recorrido cronológico repasaremos los principales factores que explican la utilización de este material a lo largo del tiempo, de la mano de los principales creadores de cada momento.

\section{Palabras clave}

Zaragoza, cerámica, arte público.

\begin{abstract}
This article analyses the evolution of the ceramic cultural legacy in the city of Zaragoza from the forties in the XXth century to the beginning of the XXIst century. We will make a chronological summary to revise the main factors explaining the use of this material by some of the most important artists of each period.
\end{abstract}

\section{Keywords}

Zaragoza, ceramic, public art. 
Referencia normalizada: ARILLA SATUÉ, SONIA (2016): “Cerámica artística en los espacios públicos de la ciudad de Zaragoza". Arte y Ciudad. Revista de Investigación, no 9 (abril), págs. 155-182. Madrid. Grupo de Investigación Arte, Arquitectura y Comunicación en la Ciudad Contemporánea, Universidad Complutense de Madrid.

Sumario: 1.- Introducción. 2.- Primeros años de la Dictadura. 3.- Del final de la Dictadura a la Transición. Años sesenta y setenta. 4.- Colectivos de ceramistas en los años ochenta. 5.- El renacimiento de la cerámica en los años noventa. 6.- Cerámica en el Frente Fluvial. 7.- Bibliografía.

\section{1.- Introducción.}

La historia de la ciudad es la historia de su espacio público, configurado éste por las relaciones entre los ciudadanos y el poder, expresados en lugares de encuentro como calles, plazas, parques o jardines, donde se instalan los monumentos y donde las fachadas se tratan en numerosas ocasiones con efectos artísticos. La heterogeneidad y fragmentación histórica de las ciudades, en las que conviven símbolos de distintas épocas, identifican a cada pueblo, que tiene rasgos distintivos.

Uno de los rasgos distintivos de la ciudad de Zaragoza es la cerámica, que está presente en los edificios mudéjares y perdura revitalizada y actualizada en los murales contemporáneos, desde los primeros azulejos diseñados por Santiago Lagunas en la década de los cuarenta a las propuestas más modernas creadas con motivo de la celebración de la Expo Zaragoza 2008.

A pesar de esta contribución a la configuración del espacio público zaragozano, la cerámica suele pasar desaperciba al transeúnte. Sin embargo, esta invisibilidad no está en relación ni a la cantidad ni a la calidad artística de los ejemplos que encontramos en calles y parques. Por tanto, en este artículo nos ocuparemos de aquellas obras ejecutadas en cerámica en la ciudad de Zaragoza, desde los años cuarenta hasta la actualidad, siguiendo un trazado cronológico, lo que nos permitirá comprender su evolución en los diferentes períodos marcados y su localización en los diferentes barrios según el desarrollo urbanístico de la ciudad. 


\section{Primeros años de la Dictadura.}

Después de la Guerra Civil, gran parte de los edificios construidos en Zaragoza se inscriben en una corriente historicista de raigambre local, reinterpretando las formas arquitectónicas del pasado consideradas representantes de la tradición de la ciudad. Un ejemplo lo encontramos en el edificio situado en la calle Manuela Sancho no 33. Construido en 1943 por Santiago Lagunas, en el que hace uso de azulejos tradicionales, similares a los de Muel, en los que trasciende el cuidado de una artesanía que era el perfecto complemento de la arquitectura mudéjar. No se trata de azulejos diseñados por Lagunas, pero en ellos se intuye su gusto por la cerámica, por el color y los valores pictóricos que ésta otorgaba a su arquitectura.

Santiago Lagunas había trabajado para Regiones Devastadas en el Valle del Ebro, donde se siguió el modelo de arquitectura palaciega de los siglos XVI y XVII, especialmente en aquellos edificios de mayor relevancia, como los ayuntamientos. Desde la Dirección General de Regiones Devastadas se insistía en la decoración con elementos populares que definiesen el carácter de cada región o comarca y que podían ser utilizados en los nuevos pueblos. Un nuevo tradicionalismo regionalista que se oponía a la lógica del Movimiento Moderno. Pero más allá de una cuestión formal, se trata de una reivindicación ideológica de corte fascista que proclamaba "dar tierra a los campesinos y la necesidad de crear un hombre antiurbano y antiobrero, ligado a la tierra y devoto del régimen, del cual es deudor de todo" (Rivero, 2005: 79). Una oposición a la modernidad, la ciudad, la técnica y la reproducción seriada, que llevaba implícita el nihilismo técnico y la abstracción formal. A esta revalorización de lo tradicional frente a la novedad y lo urbano hay que sumar las precarias condiciones económicas de los años cuarenta y la deficiente mano de obra, lo que forzó la recuperación de materiales baratos y la puesta en marcha de técnicas más arcaicas en la construcción ${ }^{1}$.

En 1946 Santiago Lagunas plantea un edificio original y atractivo desde el punto de vista formal, el Hospital San Juan de Dios de Zaragoza, terminado en 1953. Gonzalo M. Borrás Gualis no alberga duda alguna sobre el hecho de

\footnotetext{
${ }^{1}$ Un ejemplo lo encontramos en la parroquia de Nuestra Señora del Rosario, en la carretera de Extremadura, en Madrid, del arquitecto Luis Laorga, decorada en el exterior con cerámicas de Carlos Pascual de Lara realizadas en la Escuela de Cerámica de Madrid.
} 
que Lagunas tuvo presente la tradición de la arquitectura del Renacimiento aragonés, tanto en la composición arquitectónica como en la decoración (Borrás, 1997: 38) ${ }^{2}$. El edificio, construido con ladrillo a cara vista, se caracteriza por la sencillez de sus líneas. Para aligerar la severidad de la fachada principal, refuerza su expresividad gracias a elementos como los torreones cilíndricos rematados por chapiteles cónicos revestidos de pequeñas piezas de cerámica vidriada en bandas azules y blancas y azulejos sobre las ventanas de las plantas inferiores y entre las enjutas de las ventanas de la tercera, que le otorgan un peculiar sentido plástico. Precisamente son los azulejos, de temática religiosa, los que le aportan la originalidad y modernidad. En general se trata de composiciones simétricas, adaptadas a la disposición del azulejo. Con trazos simples consigue sintetizar formas e ideas. Los trazos seguros y firmes revelan su energía interior y su gran sensibilidad ante los temas religiosos. Algunos de los diseños recuerdan a sus obras de finales de los cuarenta como Peces negros y grises (1949), Ángeles de la muerte (1949) o Primavera (1949), así como unas ilustraciones publicadas en la revista ANSI en el número 1 de noviembre de 1952 y en el número 6 de 1954 (Arilla, 2014: 19). Unos diseños demasiado modernos para la Orden Hospitalaria de San Juan de Dios, que se quejaba de su "simplicidad ultramoderna, harto caprichosa" en las páginas de Labor Hospitalaria (Anónimo, 1953: 180)

Con el fin del aislamiento, la retirada diplomática y el cierre de las fronteras en 1949, se produce una apertura en el terreno de la arquitectura. La necesidad del régimen de ser aceptado en el mundo exterior, permitió una cierta flexibilización de los criterios oficiales. Por su parte, la Dirección General de Arquitectura se modernizó, aunque fuera artificialmente, lo que propició la renovación y una vuelta a las preocupaciones arquitectónicas anteriores a la guerra, es decir, el racionalismo, el funcionalismo, los espacios verdes, etc. No obstante, se mantuvo la tensión entre el tradicionalismo y la apertura.

Zaragoza, fue uno de los focos del país donde el debate artístico cobró mayor dureza. El movimiento renovador, iniciado de la mano del Grupo Pórtico en 1947, fue incomprendido y atacado en la prensa local. No obstante el espíritu renovador de Lagunas se vislumbra en el Cine de Borja (1946) en el que al-

\footnotetext{
${ }^{2}$ En particular, se refiere a la Casa de Don Pedro Martínez de Luna, Conde de Morata, en Zaragoza (actual Audiencia).
} 
canza un lenguaje personal, lejos de cualquier connotación historicista y se ejemplifica en la decoración del Cine Dorado (1949). En el Cine Dorado la arquitectura y demás artes plásticas se funden adquiriendo una nueva dimensión y su total integración. Se realiza en el momento que forma parte del grupo Pórtico con los pintores Fermín Aguayo y Eloy Laguardia, que le ayudaron en la decoración del cine. Por los bocetos y fotografías conservados sabemos que ésta era de colores vivos y alegres y podemos reconstruir aproximadamente la distribución de los diferentes motivos, entre los que se incluían dos murales cerámicos que fueron colocados a ambos lados de la barra del bar, de $1 \times 1,50 \mathrm{~m}$ aproximadamente (García Guatas, 1990: 20). Las representaciones de los dos murales cerámicos se corresponden con las obras pictóricas de finales del año 1949. Se trata de representaciones figurativas de tipo cubista en la que se distinguen algunos objetos: una vasija, una botella, unos peces, pero reducidos a sus atributos esenciales, a base de la geometrización de los volúmenes, marcados por líneas de contorno que compartimentan las zonas de color.

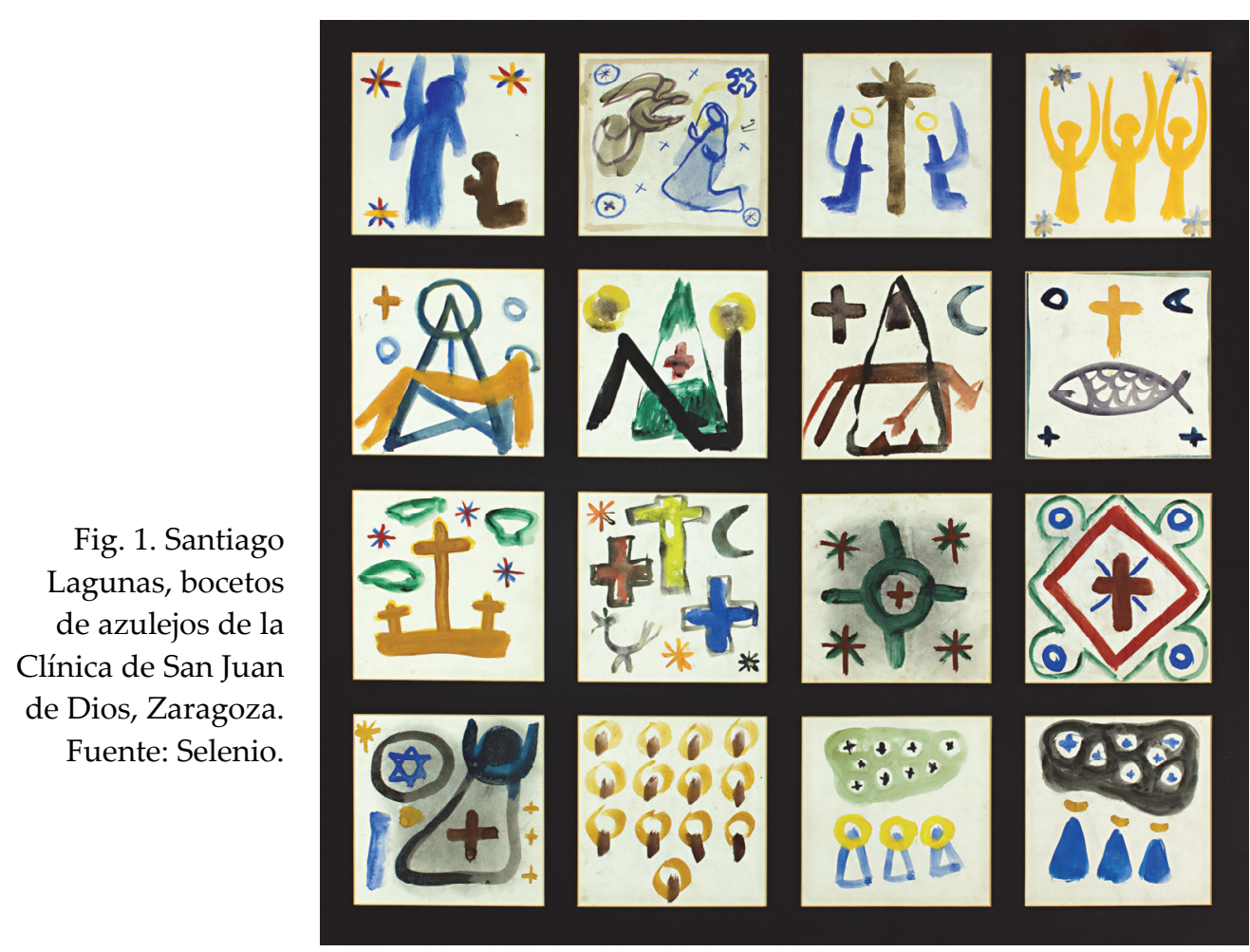


Sin duda en este proyecto Lagunas se muestra como un artista total y con una decidida voluntad de recuperar la unión entre las artes. Un tema que fue objeto de profunda reflexión y debate a lo largo de la segunda mitad del siglo XX tal y como se refleja en las revistas especializadas, que daban cuenta de declaraciones de teóricos y artistas a favor de la misma, a la par que publicaban artículos sobre proyectos en los que se buscaba dicha integración ${ }^{3}$.

Esta pretendida humanización del arte, provocó que estos años fueran pródigos en esculturas y relieves en edificios públicos y privados. Hecho que para el crítico Alexander Cirici se debía, en parte, a una moda promovida por Mussolini y copiada en España, "que obligó a que todos los edificios importantes dedicasen un cierto porcentaje de su presupuesto a pintura y escultura" (Cirici, 1977: 150). Como consecuencia los edificios se revistieron de una retórica monumentalista exterior y de los recursos semánticos exigidos por el franquismo.

Desde los años cuarenta, pero especialmente en la década de los cincuenta, la cerámica se convirtió en una alternativa a la pintura para embellecer las iglesias nuevas ${ }^{4}$ y los nuevos edificios como hoteles, aeropuertos o sedes de empresas. Algunos factores permiten explicar esta expansión en el uso de la cerámica. En primer lugar, el ya comentado debate sobre la síntesis de la artes que existía en el mundo del arte en general y entre los arquitectos en particular. En segundo lugar, las consideraciones económicas, "pues el valor base del material cerámico era poco elevado y se podían hacer obras que en cualquier otro material hubieran sido imposibles" (Blasco y Sánchez, 1962: 38). Debido a esta escasez de recursos, muchos artistas plásticos se vieron seducidos por la cerámica ${ }^{5}$. En este proceso tuvo un papel señalado la intervención de artistas de otros campos que demostraron la capacidad expresiva de un modo original y con total libertad. Es el caso de Picasso, Lucio Fontana o Joan Miró, que liberaron sus creaciones de cualquier pretensión utilitaria. También es reseñable la intervención de arquitectos como Miguel Durán Loriga y Jesús Marti-

\footnotetext{
${ }^{3}$ Como el dedicado a la reforma del Cine Dorado publicado en el número 95 de la Revista Nacional de Arquitectura.

${ }^{4}$ Un ejemplo representativo lo encontramos en el mural de Arcadio Blasco para la iglesia del Pueblo Nuevo de Bullaque en 1956 o en el viacrucis de Antonio Suárez para la iglesia de Vegaviana.

${ }^{5}$ Entre los artistas plásticos españoles citar a César Manrique, Jorge Oteiza, José Alfonso Cuní, y los ya aludidos Arcadio Blasco y Antonio Suárez.
} 
tegui, que defienden que la cerámica es el material idóneo para la decoración de edificios por su durabilidad, resistencia, calidad textural, color y por sus precios bajos y fácil acceso al material.

En tercer lugar, el deseo de experimentar con nuevos materiales, que no fue más que una consecución lógica de sus necesidades expresivas, propiciadas por la falta de medios. En las obras de estos años ningún material era desdeñado: cemento, esmaltes, papeles, barnices, metal, madera, todo podía tener una significación artística adecuada, la cerámica también.

Y, en cuarto lugar, los avances técnicos que dieron cerámicas de gran dureza y resistencia. Precisamente serán los avances técnicos (hornos eléctricos y de gas, hornos túnel, líneas de esmaltado automático, fabricación de gres vidriado siguiendo el proceso de bicocción, nuevos materiales como el Cermet, etc.) los que permitieron que desde finales de los cincuenta se investigase en torno a la tridimensionalidad, acercándose las cerámicas a los volúmenes de las esculturas. Aunque en un primer momento se trabajó con los tradicionales azulejos pintados como si se tratase de óleos, comienzan a surgir murales con infinidad de texturas, relieves, modelados e incisiones. Unos avances que proporcionaron unas cerámicas más resistentes a las oscilaciones técnicas, totalmente impermeables e inatacables por humos y ácidos, lo que las convertía en perfectamente aptas para su uso en el espacio público.

\section{Del final de la Dictadura a la Transición. Años sesenta y setenta.}

A pesar de la vanguardia representada por Lagunas, la renovación de la cerámica aragonesa no se produce hasta principios de la década de los sesenta, cuando se asienta en Zaragoza Eduardo Alfonso Cuní. En 1962 recibe el primer encargo para la entonces Caja de Ahorros y Monte de Piedad de Zaragoza, Aragón y Rioja, lo que condiciona su traslado a Zaragoza de donde su mujer es originaria. Aquí vive hasta 1965, año en que se trasladan a Teyá (Barcelona), donde monta su taller. Durante su estancia en la capital aragonesa conoce a Federico Torralba, que le pone en contacto con los arquitectos José de Yarza García y Teodoro Ríos Usón, que están buscando un ceramista para colaborar en el Hotel Goya ${ }^{6}$ de Zaragoza. Este proyecto es el inicio de una ${ }^{6}$ El proyecto de construcción del Hotel Goya es parte de uno mayor -proyectado bajo iniciativa
privada de la empresa Zaragoza Urbana S.A.-, consistente en la construcción de un hotel, un 
larga y fructífera relación, ya que Cuní deja buena muestra de su arte en muchos de los edificios proyectados por ambos. Cuní explica así su colaboración con estos arquitectos:

Ellos vieron las posibilidades de una incorporación de la cerámica a sus edificios, no sólo por las cualidades de dureza y resistencia a la abrasión y los agentes atmosféricos de la cerámica de alta temperatura empleada en exteriores, sino también por sus cualidades estéticas, como medio para singularizar un edificio (Anónimo, 1982: 34).

En sus obras estudia el proyecto y la integración de la cerámica en el edificio de manera que resultase un todo armónico y los espacios dieran respuesta a las necesidades espirituales del hombre.

Artista y arquitectos, creían en el papel social del arte y en los beneficios de una colaboración mutua. Pensaban que lo ideal era una colaboración desde el principio, de tal forma que no pudiera diferenciarse los límites de actuación de los distintos profesionales implicados en el proceso de trabajo. Una teoría ya defendida por Gropious en la Bauhaus y difundida desde finales de la década de los cuarenta por Le Corbusier o José Luis Sert, entre otros.

Zaragoza en los años sesenta es una ciudad en expansión. En 1964 es declarada Polo de Desarrollo Industrial, lo que produce la atracción de numerosa población inmigrante, procedente fundamentalmente de zonas rurales limítrofes. Por otro lado se produce un despliegue económico que provoca que se construyan infraestructuras hoteleras, se abran galerías de arte, cines, restaurantes y cafés, en los que la presencia de la cerámica artística es habitual. Una práctica que revelaba una nueva forma de entender la presencia de la obra de arte en la ciudad, desligada de la tradicional colocación de esculturas y monumentos. Este diálogo plástico será más importante en los edificios construidos por iniciativa privada, en la que los arquitectos tenían mayor libertad para escoger a los artistas con los que trabajar.

pasaje comercial, dos cines (Palafox y Rex) y un edificio de viviendas y oficinas. Los sucesivos proyectos y las obras de construcción de todo el conjunto estuvieron a cargo de los arquitectos Teodoro Ríos Usón y José de Yarza García. Se comenzó la construcción del hotel en 1952, pero con el tiempo se fue transformando para adaptarse a las necesidades de los clientes. En 1964 se incluyen varias obras de Cuní: un mural cerámico en el restaurante $\left(36,5 \mathrm{~m}^{2}\right)$, dos columnas de hierro forjado y cobre (de 3,5 m de altura) y cuatro esgrafiados sobre estuco en el hall. 
La mayor parte del arte público en la ciudad de Zaragoza durante estas décadas lo encontramos en la zona centro, especialmente en la zona comprendida entre las calles Paseo de Pamplona, Cesar Augusto, Coso y Paseo de Independencia, y adyacentes, donde gran número de edificios están decorados con cerámicas. Unas cerámicas en las que destaca la ausencia de cualquier tipo de retórica, existiendo gran equilibrio entre los modernos edificios y las obras artísticas que los acompañan.

La cerámica de Eduardo Alfonso Cuní se distingue por la búsqueda de la perfección técnica, las calidades texturales y formas táctiles a través de grafismos, huellas incisas y el modelado. Buen ejemplo de ello son los murales situados en la calle San Miguel número 12 e Isaac Peral números 1 y 1 duplicado de Zaragoza, realizados en 1966. Inspirándose en la naturaleza, busca la calidad de la piedra, para lo que cuece a alta temperatura, haciendo estallar la materia que se abre en toda suerte de cráteres. A esta experimentación material une su fascinación por los esmaltes cerámicos, que emplea en múltiples capas, creando un juego de texturas impredecible. El resultado obtenido semeja a piedras naturales que el tiempo se ha encargado de modelar.

Fig. 2 - Eduardo Alfonso Cuní, calle San Miguel no 12, Zaragoza. Fuente: S. Arilla.

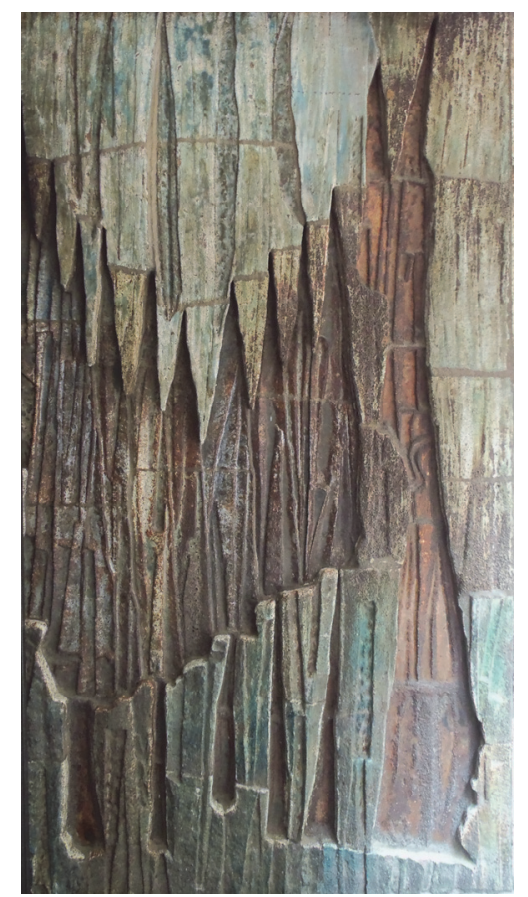


Eduardo Alfonso Cuní trata de dominar el fuego para conseguir la fuerza, los colores y las texturas de la naturaleza, desde la transparencia y el brillo del agua a la rugosidad de una piedra, como en la fuente situada enfrente del Edificio Capitán Portolés (1974), sede de la empresa Zaragoza Urbana S.A. Una escultura que en origen se acompañaba de un mural situado en la fachada principal del hotel Palafox, propiedad de la misma entidad.

Su paleta cromática es de una gran variedad, yendo del blanco al negro, pasando por los azules, verdes, rojos y sus inconfundibles marrones. Colores que prepara él personalmente. Junto a ellos, el color rojo que le atrajo después de comprobar la dificultad para obtenerlo en alta temperatura y tras admirar los espléndidos rojos chinos. Los vidriados rojos de cobre, obtenidos con gran maestría por los ceramistas chinos son, para él, la clave para dominar todos los demás colores. Un buen ejemplo de estos rojos de cobre, conocidos por el nombre de "sangre de buey", lo hallamos en el mural que se encuentra en la entrada del edificio de la plaza de Aragón nº 7 de Zaragoza (1971), en el que también destacan los esmaltes azul cobalto.

En otras ocasiones la inspiración la encuentra en oriente, que le fascinó desde que en 1960 entra en contacto con el arte y la cerámica china en un viaje realizado a Londres ${ }^{7}$. A partir de entonces tratará de emular la perfección técnica y la delicadeza de sus esmaltes. Especial admiración siente hacia la caligrafía china y sus perfectos trazos. Un ejemplo lo encontramos en el mural situado a la entrada del edificio de la calle León XIII, nº 5 (1970).

Junto a Eduardo A. Cuní destaca la figura de Andrés Galdeano, clave en la renovación de la cerámica aragonesa. Natural de Arcos de la Frontera (Cádiz) pero asentado en Zaragoza con su familia desde 1959. A pesar de tener una formación autodidacta, en 1967 crea El Alfar8, una empresa artesanal de cerámica artística, con una producción comercial y, en 1969 Muresa (Murales y Recubrimientos S.A.), una fábrica de cerámica industrial y artística, que como otras coetáneas creó numerosos murales cerámicos para su integración en la arquitectura.

\footnotetext{
${ }^{7}$ Arte chino que conoció en las colecciones del British Museum, Victoria \& Albert Museum y la David Percival Foundation of Chinese Art, sintiéndose especialmente atraído por las cerámicas de las dinastías Han, Tang y Song de los siglos III al XIII.

${ }^{8}$ Empresa montada junto a Isabel López Giménez, recién diplomada en la Escuela de Artes de Zaragoza en la especialidad de Esmaltes (Entrevista realizada a Isabel López el 28/10/2011).
} 
En sus comienzos, los murales de Galdeano se caracterizan por un barroquismo que afecta tanto al color como a las formas, además de la búsqueda de texturas. En la superficie se aprecian todo tipo de incisiones y huellas, aparentemente anárquicas (círculos, ondulaciones, rectángulos, espirales, caminos sin destino,...), un rigor constructivo que ordena los elementos y un rico colorido, con rojos y naranjas y las gamas de azules y verdes, con los que crea un mundo de fantasía con una poética totalmente personal. Unas obras que podemos clasificar dentro del expresionismo abstracto, con derivaciones de signo y gesto, visible en el fluir de la mano. Representativos de esta etapa son los murales situados en el Edificio Asís (1970), en la entrada del edificio situado en la calle Juan II de Aragón (1970) o en el mural ejecutado para la casa del Paseo de Pamplona, número 4-6 (1971). En este último se refleja muy bien la influencia del jazz, visible en la inscripción "coltrane", un homenaje al saxofonista John Coltrane, que se traduce en una trasposición del desgarrado sonido de este músico a la cerámica.

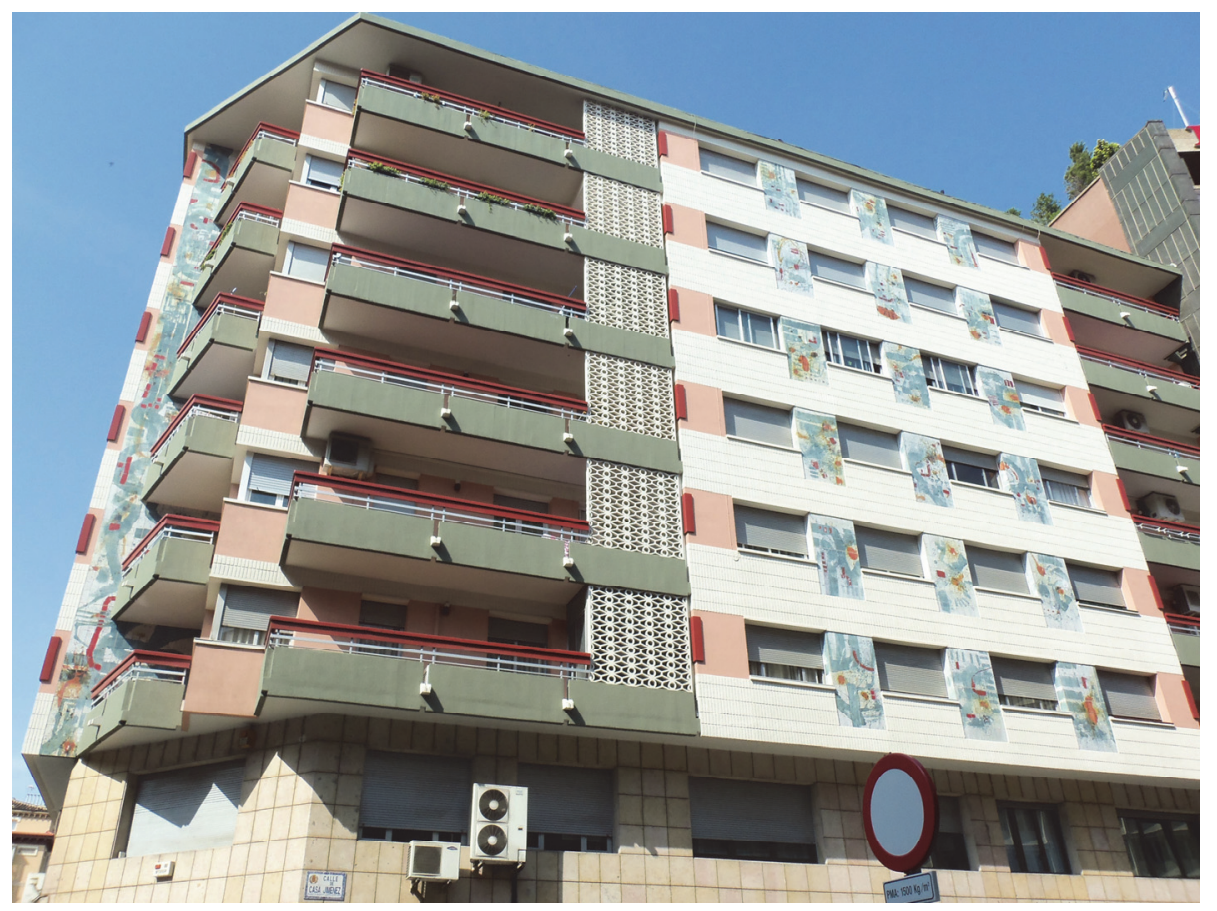

Fig. 3. Galdeano, Edificio Asís, calle José Luis Albareda no 6 - calle Bilbao no 2 - calle Casa Jiménez s/n, Zaragoza. Fuente: S. Arilla. 
Las mismas formas trabajadas, incisiones y grafismos los encontramos en el mural realizado para la Galería Galdeano (1970) ${ }^{9}$, situada en la calle Santa Isabel, con la diferencia de que este mural carece de color, o mejor dicho, tiene el color de la arcilla, que transmite una sensación de contención propia de los materiales no embellecidos. Galdeano trabajaba sus murales en el suelo, incidiendo con diferentes objetos sobre la arcilla húmeda, quedando su impresión marcada, como pueda ser en este caso la de una bicicleta o las huellas de su perra Nuna. Pero sin duda el encargo más importante de estos años fueron los murales realizados para la nueva estación de ferrocarril El Portillo de 1971, para la que realizó dos grandes murales cerámicos para el interior de la estación, uno más pequeño para las escaleras de acceso a la primera planta y otro de hierro para el exterior. Un edificio que recibió el prestigioso premio Ricardo Magdalena de la Institución "Fernando el Católico", hecho que le procuró numerosos encargos dentro y fuera de la ciudad.

En 1973 comienza un período de mayor simplicidad y contención. El punto de inflexión lo marca la colaboración con Manuel Viola para los murales de la sede de Campsa en Madrid. A partir de entonces entra en una etapa de mayor sencillez, emplea sólo dos o tres colores en cada obra, abandona el expresionismo anterior y se adentra en un enfoque más geométrico y en la experimentación con volúmenes, que otorga a sus obras un carácter más escultórico. Sin duda una de las obras más representativas de este momento son los murales para la sede central de la Caja de Ahorros de la Inmaculada en el Paseo de la Independencia, ejecutados en 1977. Se trata de murales en colores tierra y marrones que se integran perfectamente en la arquitectura, acompañando a los visitantes en su acceso a la Sala CAI-Luzán y a las oficinas del piso superior.

En Muresa trabajaron otros ceramistas como Ángel Grávalos, José María González Ballesteros "Gomballest", Rosa Castro, Esperanza Grávalos "Titina”, Jesús Barranco, Cirilo Sócrates Muñoz y Alfredo Díaz "Aldi”, haciéndose con el encargo de un importante número de obras: en viviendas particulares, bares, hoteles, restaurantes y centros comerciales de la ciudad, como el Pasaje Goya o el Pasaje San Clemente, -situado en la calle del mismo nombre, per-

\footnotetext{
${ }^{9}$ La galería se inauguró el 5 de mayo de 1967 con una exposición del ceramista Segú y se clau-
} suró en mayo de 1971 con una exposición de Millares. 
pendicular al Paseo de la Independencia-. Este mural, realizado en 1975 por Aldi y Barranco es de carácter escultórico, con relieves acentuados, cuyo tema central es una flor a modo de espiral, como símbolo eterno, principio de la energía y de la expansión.

Desde los años treinta la expansión de la ciudad hacia el sur es imparable. A mitad de la calle Fernando el Católico se encuentra la Universidad de Zaragoza, en la que encontramos obras cerámicas en el hall de la Facultad de Filosofía y Letras y en el Rectorado. Murales que fueron realizados por Ángel Grávalos, aparejador de la Caja de Ahorros de la Inmaculada y co-fundador de Muresa. Su cerámica es de superficies muy trabajadas y colores brillantes, con tendencia a la geometrización de las formas.

En el edificio de la Facultad de Filosofía y Letras, proyectado en 1935 por José Beltrán Navarro y Regino Borobio Ojeda destaca en el hall de entrada la decoración mural de baldosas cerámicas de Grávalos de 1972. Los motivos figurativos que los decoran se inspiran en temas cervantinos y goyescos, el escudo de la Universidad e inscripciones de tipo paleográfico. Predominan los tonos azulados con aplicaciones de tonos tierra y ocre.

El edificio Interfacultades y Rectorado fue proyectado en 1970 por el arquitecto Isidoro Garasa Collado. Poco después de construido, el edificio Interfacultades se decoró con una escultura realizada en 1973 con placas de metal de Ángel Grávalos, que se colocó en el hall de entrada. Para el edificio del Rectorado diseñó un mural que recorre a modo de friso tres de las fachadas ${ }^{10}$. A pesar de que la cerámica no está vidriada, consigue un gran dinamismo gracias a las formas geométricas que recorren la superficie: círculos, curvas, líneas rectas, huellas incisas, etc., en una manera de trabajar similar a la de Galdeano.

Al principio de la calle San Juan de la Cruz, perpendicular a Fernando el Católico, nos encontramos con otro mural característico de estos años. Fue realizado en 1976 por Carlos Bartolomé García, conocido artísticamente como "Bartol", para la tienda Potter (palabra inglesa que significa "ceramista"). El

\footnotetext{
${ }^{10}$ Muy parecido a este friso son los ejecutados hacia 1973 para el Edificio de las Américas de Barcelona, aunque en este caso, la cerámica si está vidriada, consiguiendo romper la monotonía y logrando un mayor dinamismo en la composición.
} 
mural, que debía de servir de reclamo al establecimiento, decora gran parte de las dos fachadas de la tienda, que originariamente estaba dedicada a la venta de objetos de arte decorativos ${ }^{11}$. La composición, de color verde, es marcadamente geométrica, sólo rota a través de pequeños relieves de los que parten líneas sinuosas de colores fuertes, rojos, amarillos y marrones que le confieren mayor vivacidad.

La expansión continua hacia el sur y pronto se sobrepasaron los límites del Parque Primo de Rivera (actualmente Parque José Antonio Labordeta) a partir de la formación de la calle Isabel la Católica -continuación de Fernando el Católico-, vía en la que se encuentran edificios emblemáticos como la Residencia Sanitaria José Antonio (actualmente Hospital Miguel Servet), la Feria Oficial y Nacional de Muestras (hoy Cámara de Comercio, 1948-1958) o el campo de fútbol de "La Romareda", construido en 1957. La presencia de estos tres edificios condicionó el desarrollo del llamado polígona de la Gran Vía, destinado mayoritariamente para fines residenciales. Por aquel entonces $\mathrm{Mu}$ resa estaba en pleno funcionamiento y la cerámica estaba de moda en la ciudad, por lo que muchos bloques de edificios del polígono cuentan con murales cerámicos en sus accesos.

Un caso singular es el mural creado para un Pabellón Deportivo ${ }^{12}$ situado en la calle Eduardo Ibarra, detrás del campo de fútbol de "La Romareda". Diseñado por Miguel Durán-Loriga y Jesús Martitegui (Alfaraz), hacia 1973, en el mural se conjugan los símbolos geométricos abstractos, como círculos con radios cruzados en su interior, con la representación figurada y estilizada de distintos deportes que se podían practicar en el Pabellón Polideportivo: natación, futbol, ciclismo, boxeo, gimnasia deportiva, salto de altura o esgrima. Un diseño que combina el trabajo industrial de los módulos en relieve de las formas geométricas y el trabajo artesanal e individualizado de las figuras humanas.

A finales de la década de los setenta Ibercaja decide erigir su sede principal en el centro de la ciudad. El lugar elegido fue la Plaza Paraíso. El edificio proyectado por Teodoro Ríos Usón en 1977 debía albergar las oficinas, un centro

${ }^{11}$ Según consta en el Archivo Municipal de Zaragoza: nº caja: 13.102 № Registro General: 16.752.

${ }^{12}$ Construido en el polígono por la Caja de Ahorros y Monte de Piedad de Zaragoza, Aragón y Rioja. Actualmente pertenece a la entidad deportiva del Fútbol Club Zaragoza. 
de congresos y sala de exposiciones. Es un edificio moderno y monumental, de paramentos acristalados verdes y cerámica de Eduardo Alfonso Cuní13 en los tres frisos que recorren la parte inferior del edificio. Los frisos tienen una superficie de $1500 \mathrm{~m}^{2}$, están decorados con motivos abstractos de cerámica blanca con matices verdes, grises y amarillos, ejecutados siguiendo técnicas chinas de celadones y reflejos de plata. Unos vidriados que tienen una transparencia que les hace cambiar de color en función de la incidencia de la luz solar.

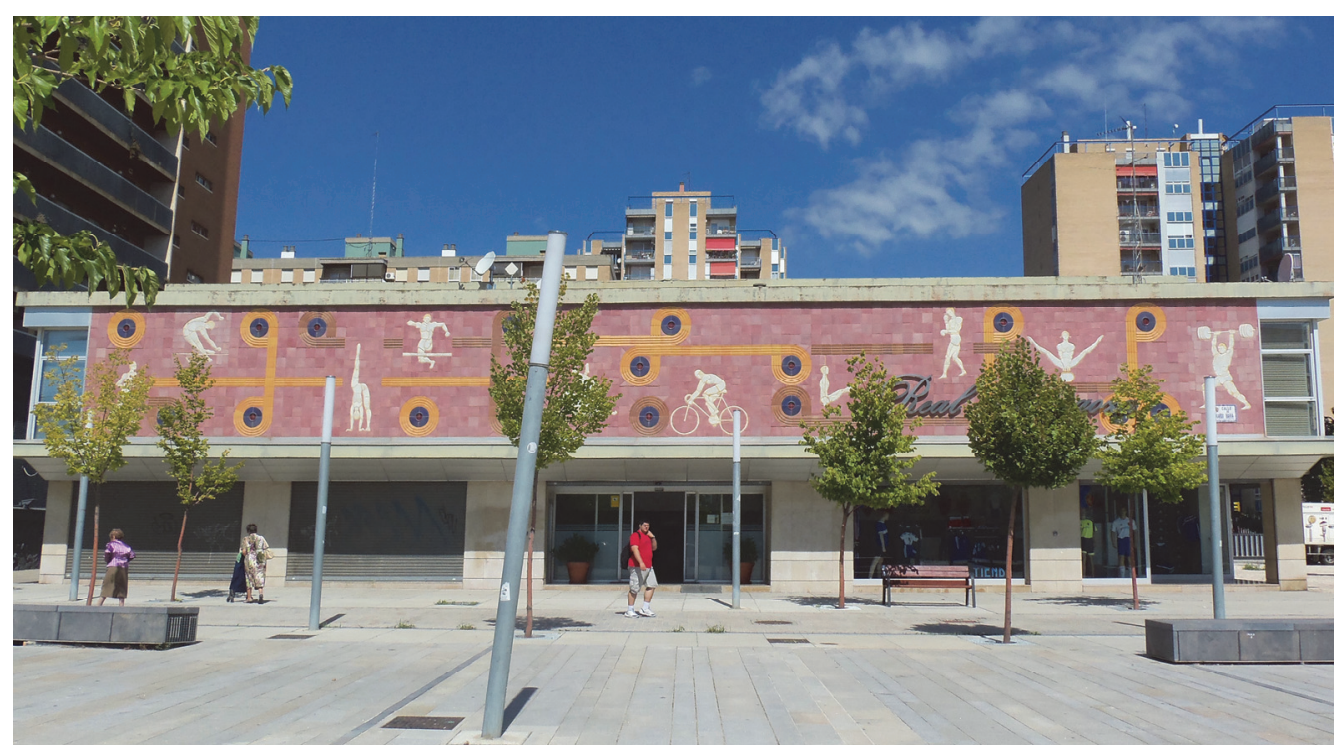

Fig. 4. Alfaraz, Tienda del Real Zaragoza, Calle Eduardo Ibarra, Zaragoza. Fuente: S. Arilla.

Seguramente se trate de uno de los trabajos que mejor ilustra las posibilidades de la cerámica en la arquitectura, en una perfecta simbiosis con el edificio y el entorno y, el culmen a una relación profesional con Teodoro Ríos que se desarrolla a lo largo de dos décadas. En el éxito del resultado es clave la colaboración directa entre ambos, el conocimiento mutuo y la forma de trabajar de Cuní, que elabora una por una todas las piezas, estudia el proyecto y la integración de la cerámica en el mismo, de modo que resulte un todo armóni-

${ }^{13}$ E. A. Cuní había colaborado anteriormente en algunas de las oficinas de la entidad financiera en distintas localidades: Ejea de los Caballeros (1963), Calahorra (1965) o la Agencia Urbana de Plaza de España no 1 de Zaragoza (1969). Con posterioridad intervino en Barcelona, en la oficina del Paseo de Gracia (1988). 
co, y no un parche añadido en el último momento. Cuní creía que la cerámica podía ser el "punto de enlace entre la naturaleza y lo artificial, entre la frialdad funcional que impone la vida moderna y el calor humano que el hombre necesita para vivir como hombre" (Alfonso, [1970]: s/p) por lo que pone su arte al servicio de la arquitectura y la ciudad.

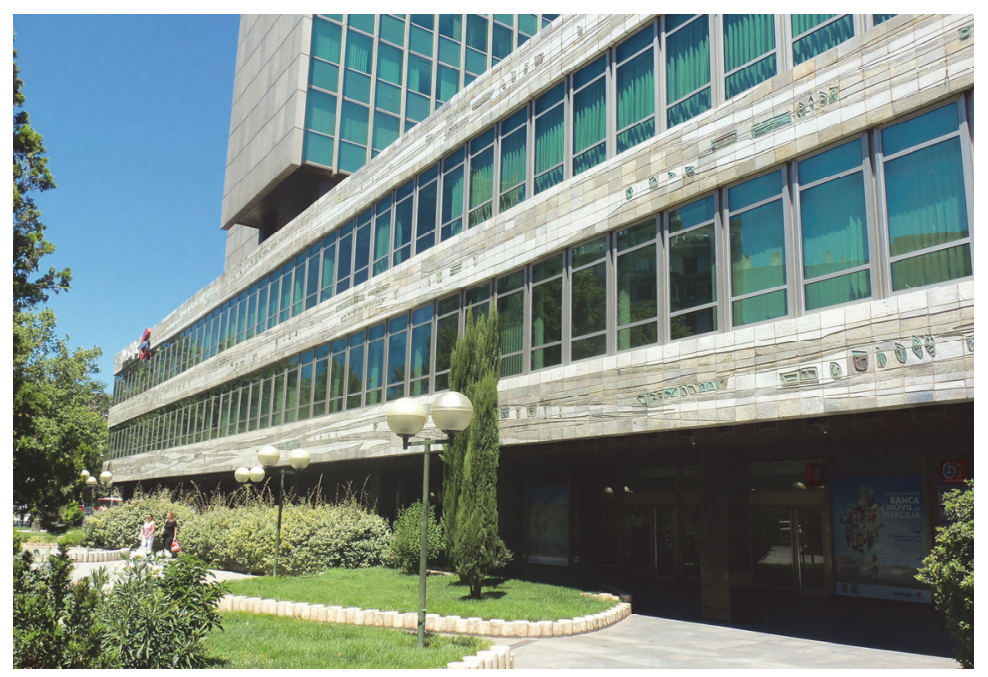

Fig. 5. Eduardo Alfonso Cuní, Sede central de Ibercaja, Plaza Paraíso, Zaragoza. Fuente: S. Arilla.

Tras la conclusión de este edificio se observa una falta de interés por la cerámica. La desaparición definitiva de Muresa en 1975 fue un aviso de que los proyectos comenzaban a escasear. Aunque Cuní, Galdeano y otros ceramistas de la empresa continuasen unos años en activo, trabajando de forma individual y mayoritariamente en el ámbito privado, los años del boom cerámico en la ciudad habían terminado. No será hasta los años ochenta cuando aparezca la siguiente generación de ceramistas, con tendencia a integrarse en distintos colectivos cuando la actividad muralista se restablezca lentamente.

\section{Colectivos de ceramistas en los años ochenta.}

En 1982 se funda el Colectivo de la Plaza San Felipe, que se reúne el primer domingo de cada mes en la plaza del mismo nombre, para mostrar sus obras y dar a conocer el trabajo de diferentes talleres aragoneses dedicados a la cerámica creativa, que poco tenía que ver con la tradicional. Los antecedentes los encontramos en algunas exposiciones celebradas anteriormente como la $I$ Muestra de Cerámica y Alfarería Aragonesa, celebrada en el Museo de Zaragoza 
en 1979 o Ayer y hoy de la cerámica aragonesa celebrada en 1982 en La Lonja. En el primer folleto, que servía de presentación del colectivo escribían:

Nos reunimos: para mostrar nuestro trabajo. Para que conozcáis de cerca el proceso creativo de la cerámica actual. Para que participéis en nuestra labor de expresión. Para elevar la cerámica a campos donde hasta ahora sólo las llamadas artes mayores han podido llegar (Ara, 2007: 32).

Entre las actividades desarrolladas para la difusión de la cerámica destaca la organización de la Feria de Cerámica Creativa, que se celebró por primera vez en 1984. Con motivo de la celebración en 1986 de la II Feria de Cerámica Creativa, los ceramistas del Colectivo San Felipe realizaron una pieza conjunta que sirvió como testimonio de las actividades del grupo. Se trata de una gran vasija decorada con óxidos y engobes que se asemeja a una vasija abierta (sin utilidad aparente) o, según otras interpretaciones, una semilla a punto de germinar. El escenario elegido para colocar la Vasija fue la Plaza de los Sitios, frente al Museo de Zaragoza y la Escuela de Artes, entablando un diálogo con la gran colección cerámica albergada en el museo. Con la escultura querían dejar testimonio de las actividades celebradas, difundir la cerámica artística a la vez que la diferenciaban de la tradicional.

Algunos de los participantes en los encuentros de la Plaza de San Felipe se agruparon en el denominado Cerámica y Ceramistas, integrado por Amado Lara, Fernando Malo, Ángeles Casas, La Huerva (Javier Fanlo, Montse Mazas, Esther Mazas), Juan A., Jiménez, Joaquín Vidal y Susana Santamaría. En diciembre de 1985 deciden abrir en pleno centro de Zaragoza una tienda donde vender las piezas del grupo y organizar actividades, así como una sala de exposiciones ${ }^{14}$, convirtiéndose en sus cinco años de actividad, en referencia nacional en su apuesta por la cerámica creativa. Como publicidad de las actividades, en el exterior del local, situado en la calle Santa Isabel, colocaron un mural cerámico, obra de Fernando $\mathrm{Malo}^{15}$.

Con motivo de la II Muestra de Cerámica y Alfarería Aragonesa, Ángel Azpeitia reclamaba desde las páginas del Heraldo de Aragón el reconocimiento de la cerámica como arte mayor si el "caso lo merece", poniendo el acento en la

${ }^{14}$ Se sumaba esta sala a la tienda y estudio Isiegas en la calle Lorente, cuya planta baja estaba destinada a la exposición y venta de las obras de algunos de los ceramistas del grupo.

${ }^{15} \mathrm{El}$ mural se conserva actualmente desmontado en el taller del ceramista. 
calidad y no el material. Debemos señalar que se refería a la cerámica de pequeño formato, heredera de la alfarería tradicional y no a los grandes murales de aplicación arquitectónica. No obstante, la equiparación de la cerámica a otros materiales artísticos y su consideración por parte de las entidades públicas como material idóneo para el espacio público se demoró unos años.

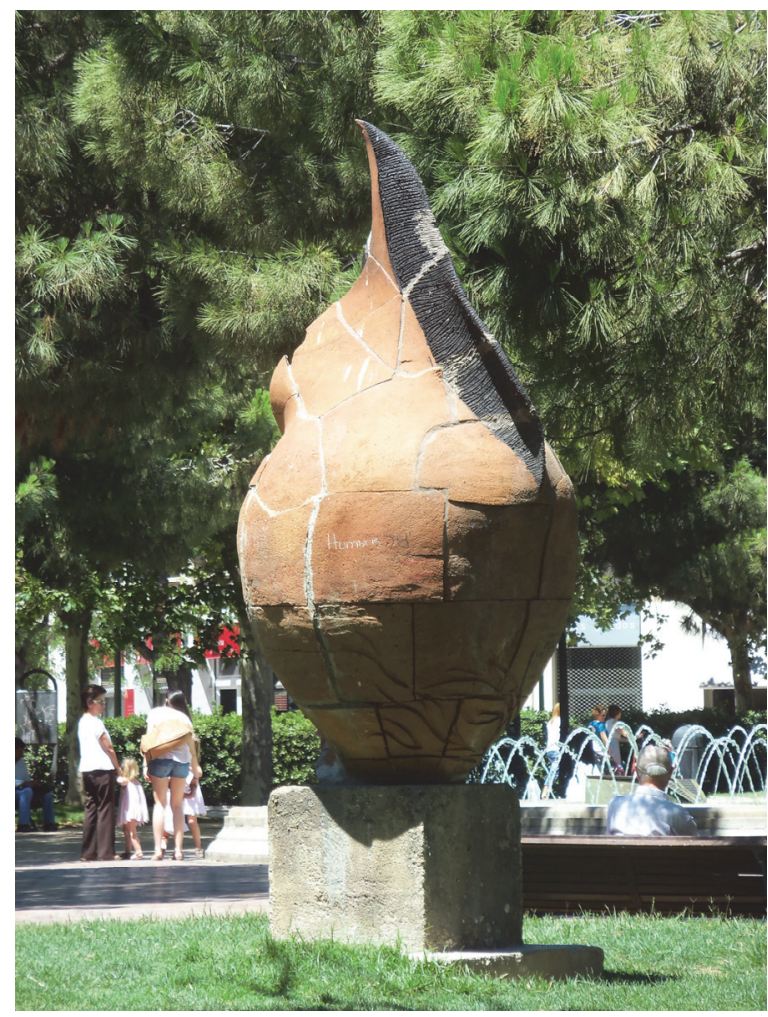

Fig. 6. Colectivo Plaza San Felipe, Vasija, Plaza de los Sitios, Zaragoza. Fuente: S. Arilla.

\section{El renacimiento de la cerámica en los años noventa.}

En los años noventa la cerámica vuelve a cobrar protagonismo en el espacio público zaragozano, en la mayoría de ocasiones gracias a la iniciativa pública a diferencia de lo acontecido en las décadas anteriores. Los nuevos emplazamientos serán los barrios periféricos del ACTUR, y fundamentalmente el barrio obrero de San José. La procedencia de los artistas sigue siendo aragonesa: Ángel Orensanz, Antonio Saura, Fidel Ferrando o Enrique Val, debido a que fueron encargos directos, sin concurso, que hubiera abierto las posibilidades de participación. 
En los años setenta se había incorporado a la ciudad la margen izquierda del Ebro para uso residencial, gracias a las Actuaciones Urbanísticas Urgentes (ACTUR). El área denominada ACTUR “Puente de Santiago" quedó fijada en 1971. Una de las características del barrio era la falta de edificios o monumentos representativos, que se palió en parte con la construcción en el eje principal de esta zona residencial del gran centro comercial Grancasa (1997), en cuyo acceso principal se ubicó un gran mural realizado por el ceramista Fidel Ferrando según diseño del pintor oscense Antonio Saura.

Sin duda contar con la autoría y firma de un artista de reconocido prestigio como Antonio Saura otorgaría al inmueble distinción, por eso se le encarga la creación de un logotipo que sirviera de identidad visual del centro comercial. La idea se plasmó en una mariposa que revoletea sobre el nombre de la entidad. Posteriormente se le propuso la creación de un gran mural que se pudiera convertir en un símbolo. En un principio se pensó en crear el muro de la entrada principal completamente recubierto de cerámica, pero se descartó por consejo de los arquitectos del proyecto, que temían que su tamaño entorpeciera su correcta visualización, quedando finalmente circunscrito a la parte superior de la puerta. Sin duda, una decisión errónea, como ya apuntaba Saura por aquel entonces.

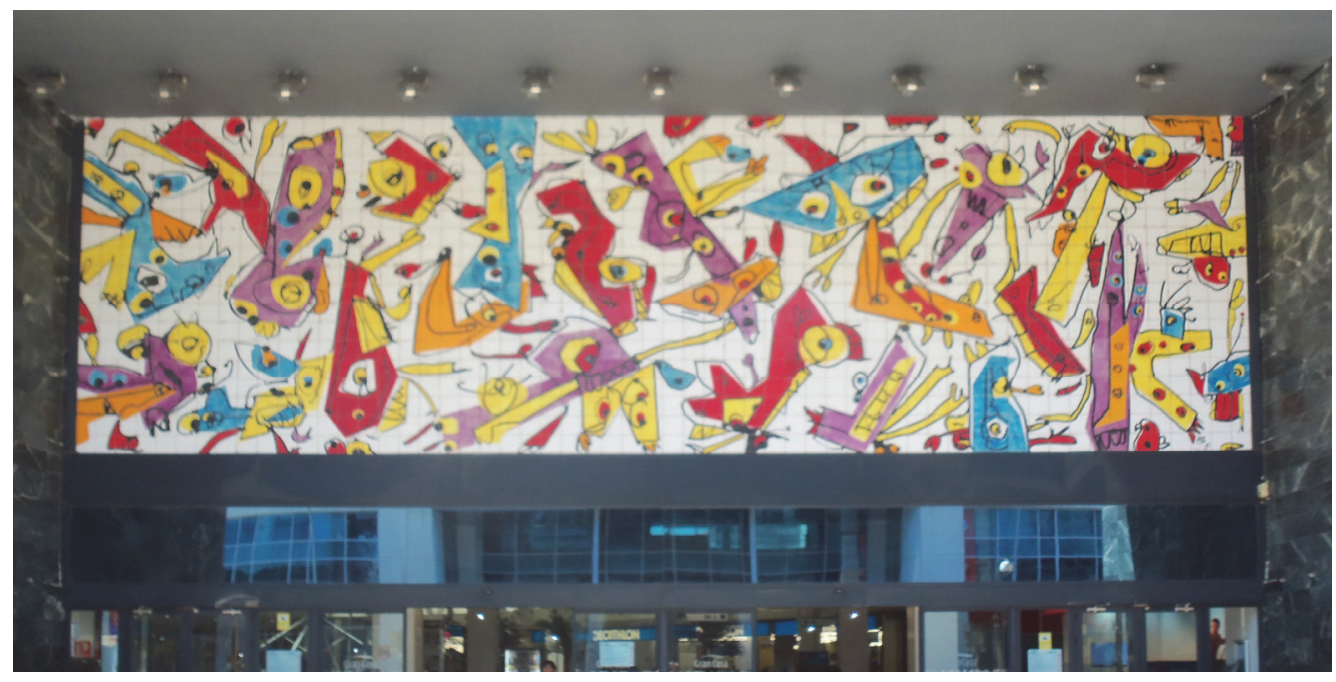

Fig. 7 Antonio Saura y Fernando Malo, Centro Comercial Grancasa, Zaragoza. Fuente: S. Arilla. 
El mural se sitúa en la órbita de la Elegía (1987) de la Diputación Provincial de Huesca. Ambos cuentan con un fondo blanco sobre el que resaltan poderosamente los brillantes colores, en un derroche de alegría y vitalidad. Destacan las figuras de color con múltiples ojos y los trazos gestuales, tan difíciles de reproducir a gran escala. El resultado proyecta una imagen de Grancasa colorista, festiva y lúdica apropiada para un centro de comercio y ocio que recibe miles de visitantes diarios.

Singular es el caso del barrio de San José, una zona de rápido crecimiento debido a la inmigración de los años sesenta y setenta. Un crecimiento que provocó problemas estructurales y la falta de equipamientos y espacios públicos. Hecho que se palió en parte con el Plan General de Ordenación Urbana de 1986, que pretendía recuperar la ciudad para el ciudadano, frenando el deterioro del centro histórico y recuperando proyectos de mejoras del equipamiento público, dentro de una política de desarrollo del espacio urbano de la periferia. Concretamente en el barrio de San José se construyeron el Parque de la Granja y el Jardín de la Memoria y se embelleció el entorno del Pabellón Príncipe Felipe.

El Parque de la Granja es una gran zona verde de 3,5 hectáreas situada en las proximidades del Pabellón Polideportivo Príncipe Felipe. Construido en dos partes, primero se levantó el colegio Calixto Ariño y el centro deportivo municipal y, alrededor, una zona ajardinada; expandiéndose posteriormente el núcleo central hasta llegar a los raíles del ferrocarril. Como mejora del Parque, Rafael Barnola Usano, Ingeniero Director del Servicio de Parques y Jardines del Excmo. Ayuntamiento de Zaragoza desde 1970, decidió realizar un monumento dedicado a la presencia de Aragón en el continente americano. Por eso, la vegetación de alrededor combina plantas mediterráneas -olivos y cipreses-, con otras americanas -palmeras y magnolios-. Ideó un monumentofuente, Aragón en la Hispanidad ${ }^{16}$ (1989) para el que contó con la ceramista Teresa Granada. El monumento se inserta en un estanque, y consta de un gran portalón trasladado de una casa derribada del casco histórico al que se aña-

\footnotetext{
${ }^{16}$ Se trata de una temática, la Hispanidad, presente en el arte público de la ciudad desde época franquista, cuando era uno de los principios ideológicos del régimen. Basten como ejemplo los dos pequeños murales cerámicos de Ángel Grávalos para el Edificio Magallanes y el Edificio El Cano, situados en la calle Juan II de Aragón.
} 
dieron dos murales de gres cerámico -uno en cada lado de la puerta-. En un lado se representa un mapa de América en el que se sitúan los nombres de las poblaciones con nombre aragonés. En el otro, el viaje de Colón a través de tres carabelas que surcan los mares; parte que da salida a tres chorros de agua.

En las proximidades del Pabellón Príncipe Felipe, en la prolongación de la Avenida Cesáreo Alierta -la antigua calle Cartagena-, se construyó una plaza rectangular aislada entre las calzadas. La parte central se elevó sobre tres plataformas y en los extremos se colocaron unas farolas metálicas que custodian la fuente central. Las farolas descansan sobre una base pétrea sobre la que se asientan unos murales de cerámica de Enrique Val, según diseño de José Carlos Marcos Foz y que representan las "Cuatro Estaciones".

En la rotonda de la confluencia de las avenidas Cesáreo Alierta y San José se ubicó una fuente compuesta por tres cuerpos de planta circular decrecientes en anchura. A su lado, se levanta una gran farola metálica, coronada en la parte superior por unos grandes focos que iluminan la glorieta. La zona inferior se recubrió con placas cerámicas muy coloristas de Enrique Val según diseño de estética cubista de Jorge Encalado.

El Jardín de la Memoria surge por la iniciativa de la Asociación de Vecinos del Barrio de San José que luchó por paliar el déficit de espacios públicos. Se ubica en el antiguo emplazamiento de la fábrica Pina, unos terrenos que el Ayuntamiento pretendía convertir en zona residencial y los vecinos del barrio querían que se dedicasen a zona verde, convirtiéndose en símbolo de su lucha. Finalmente el proyecto de los vecinos es el que sale adelante, siendo ellos los que planifican el espacio con la ayuda del arquitecto Antonio Lorenzo y de José Luis Ferrando en la jardinería. La participación de los vecinos en la conformación del parque y el hecho de que el arte público fuese uno de los principios rectores del proyecto, lo convierten en un caso particular dentro de la ciudad. Se invitó a artistas locales para que participen con alguna pieza, materializándose tres proyectos: un mural de Rubén Enciso y Fernando Malo; la figura La Bañista de Carlos Ochoa, en el espacio del pequeño estanque de Cantarranas; y dos murales cerámicos de Santiago Lagunas y Fernando Malo.

El mural de Rubén Enciso está realizado en hormigón al que se insertan piezas de cerámica de Fernando Malo. Transcurre a lo largo de un muro de casi setenta metros de trazado irregular que separa la plaza central -situada 
en la parte inferior- de la zona superior -donde se sitúa la acequia que atraviesa el parque y el estanque de Cantarrañas-. Las piezas de cerámica son independientes entre sí aunque están conectadas por líneas curvas de cerámica azul; unas recogen las huellas de las manos de los vecinos, otras representan caras, estrellas o formas abstractas, en una simbiosis perfecta con el hormigón que las cobija y que tiene incisas figuras humanas, suponemos en un reconocimiento a los vecinos de barrio por el trabajo realizado y el empeño en la consecución final del proyecto.

Los murales cerámicos de Santiago Lagunas y Fernando Malo aparecen como puerta de entrada al espacio desde la calle Royo Villanova, anunciando el nombre del espacio Jardín de la Memoria. La "puerta" de hormigón consta de una parte central hueca y a cada lado un mural cerámico. Los murales están basados en dibujos de Santiago Lagunas. El de la derecha es una traslación a la cerámica del gouache Los pájaros tristes del otoño (1981), y el de la izquierda recuerda al gouache Tres lanceros bengalíes (1981). Dibujos que se corresponden con un momento más gráfico en su producción y como en ellos, sobre un fondo blancuzco flotan formas geometrizadas negras que parecen navegar en un espacio infinito.

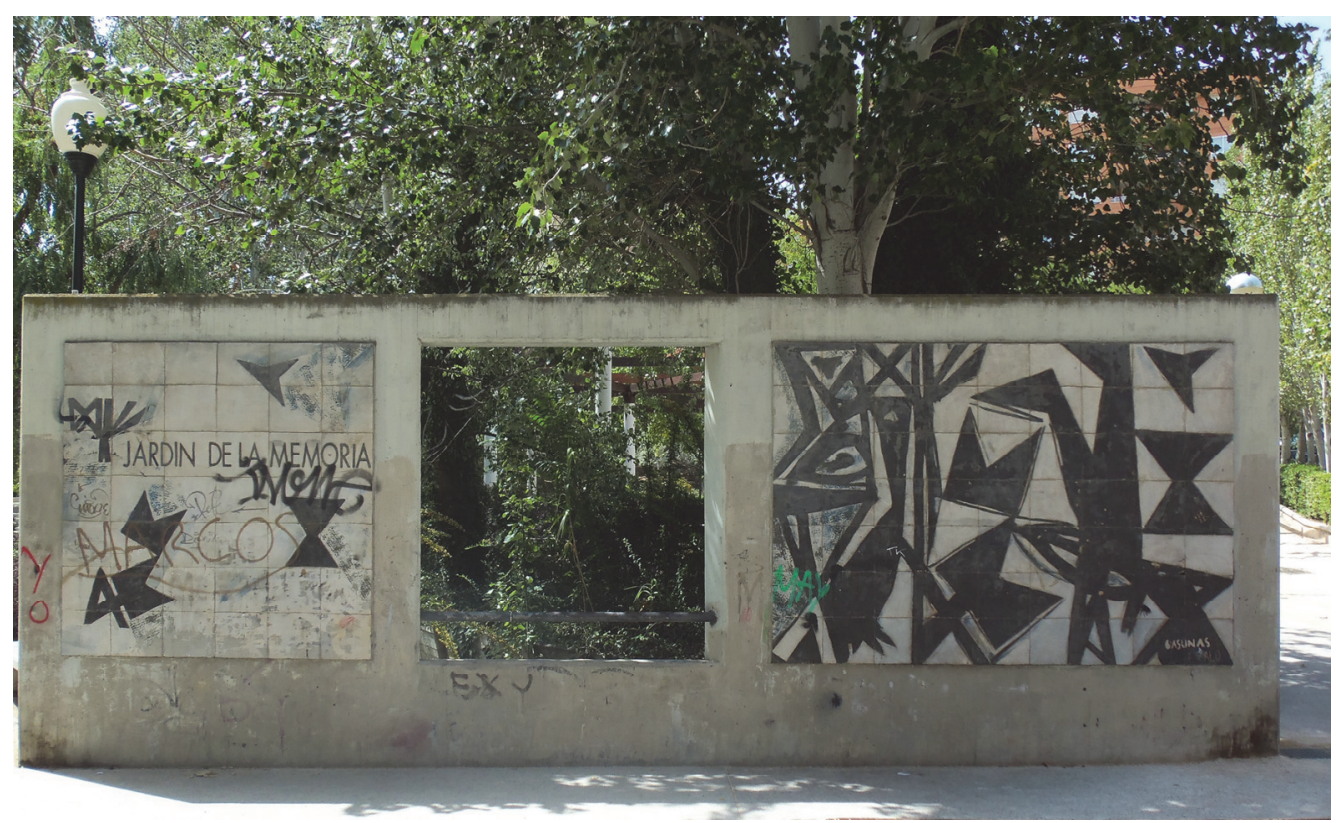

Fig. 8 Santiago Lagunas y Fernando Malo, Jardín de la Memoria, Zaragoza. Fuente: S. Arilla. 
En el centro histórico el Gobierno de Aragón encarga en 1987 a Ángel Orensanz un mural para la fachada de su sede en la Plaza de San Pedro Nolasco. El éxito cosechado en Barcelona, gracias a los murales para cinco de las estaciones de metro de la ciudad, se sintetiza en este trabajo en el que combina y contrasta partes realizadas en cerámica refractaria vidriada y partes de cemento trabajado directamente sobre el muro. Las partes cerámicas enlazan con el mural Atlantes (1975), para una entidad bancaria en Tarragona y con los murales de IBM en Boca Ratón (1980-81). Como en aquellos, aquí aparecen grafismos ondulantes, circulares u ovoides, entrecruzados por líneas que los enmarcan verticalmente. Por su parte, en las partes de cemento se alternan las figuraciones expresionistas con la abstracción geométrica. Unas formas humanoides que repetirá en los murales situados en la entrada del Centro Politécnico Superior de la Universidad de Zaragoza.

\section{Cerámica en el Frente Fluvial.}

En los últimos años la Exposición Internacional de Zaragoza 2008 marcó un hito en la renovación de los espacios urbanos de la ciudad. El tema elegido para la exposición fue: El Agua y el Desarrollo Sostenible, por lo que su ubicación cerca del río Ebro parecía la adecuada. El lugar elegido fue el meandro de Ranillas, un área de gran interés ecológico que había quedado aislado de la ciudad. La idea era relacionar el frente fluvial, física y visualmente, con la ciudad. Para la revitalización de estos espacios de la ribera se articuló la construcción de un espacio de calidad, que relacionase naturaleza y cultura y que incluía su monumentalizacion a través del arte público. Para ello, un comité internacional seleccionó para la sociedad estatal Expoagua Zaragoza 2008 las intervenciones artísticas más adecuadas.

Entre las obras seleccionadas hay que destacar la presencia del Banco Ecogeográfico del diseñador Isidro Ferrer y los arquitectos paisajistas Enric Battle y Joan Roig. Una instalación que responde a la categoría que en el concurso de Expoagua se llamó “obras muy eficaces para su integración en medios naturales o ligeramente urbanizados y su utilización pública interactiva: en zonas de descanso, contemplación, juego, etc." (García y Lorente, 2011: 10). El banco tiene 675 metros de largo, ejecutados en 20 tramos distintos, que se ondulan sinuosamente a lo largo de la orilla del río, creando espacios perfectos para descansar, conversar, comer o contemplar la ribera, cumpliendo una do- 
ble función, artística y funcional. Representa un mapa cartográfico del mundo con toda su diversidad. Su fuente de inspiración narrativa y conceptual se encuentra en la cartografía antigua y su inspiración formal en el Parque Guell de Gaudí. La obra de Gaudí está realizada con trencadís, es decir, piezas cerámicas rotas y colocadas aleatoriamente en la arquitectura para conformar un manto de color. En este caso, el millón y medio de piezas de cerámica están redondeadas, evocando los cantos rodados de los ríos y tienen colores menos llamativos que los utilizados por el arquitecto catalán, consiguiendo de forma sutil integrar arte y escultura en el paisaje.

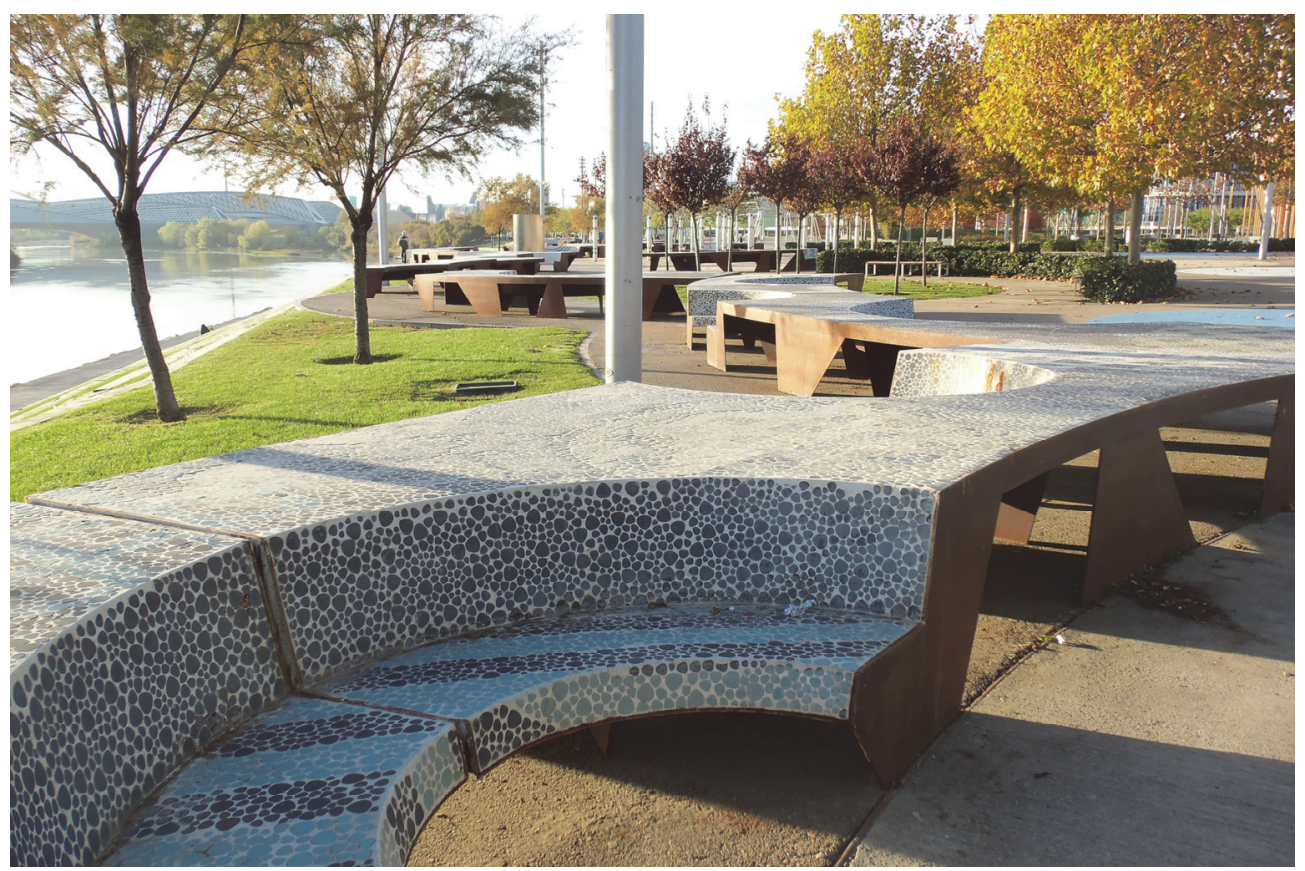

Fig. 9 Isidro Ferrer, Enric Battle y Joan Roig, Banco ecogeográfico, Frente Fluvial, Zaragoza. Fuente: S. Arilla.

Una vez concluida la muestra muchos de los pabellones desaparecieron, como el Pabellón de Iniciativas Ciudadanas, conocido como "El faro", que fue sede de distintas organizaciones sociales que participaron en la muestra. Durante la Expo fue uno de los pabellones más apreciados por los visitantes por su arquitectura sostenible, por estar construido siguiendo técnicas tradicionales y emplear materiales naturales como el barro, la paja y la madera, así co- 
mo por los intensos debates que en él tuvieron cabida. En 2009 el Ayuntamiento decidió levantar un memorial del mismo en el Frente Fluvial, en el lugar ocupado originalmente por el pabellón. Consta de dos partes: por un lado, una réplica a pequeño tamaño del propio pabellón de Fernando Nácher, realizado en resina de poliéster, carbonato cálcico y pigmento en polvo reforzado con fibra de vidrio para garantizar su resistencia y durabilidad. Y por otro, un mural cerámico que evoca la labor desarrollada en el pabellón, del ceramista Juan Jiménez y Fernando Nácher. En el centro del mural se proclama el derecho al agua y a la protección del medioambiente de todas las personas con la siguiente inscripción:

EL FARO: más de 300 organizaciones sociales (ambientales, cooperación, sociales, sindicales...), con un mensaje y voz únicos, sumaron esfuerzos por el Derecho Humano al Agua y a la Protección de los Ecosistemas Acuáticos.

En la parte derecha del mural aparece un niño blanco con los brazos abiertos, como dando las gracias por la abundancia de agua, representada por un frondoso árbol verde en lo que puede ser la ribera de un río y, en la parte izquierda, una niña africana con una vasija en la cabeza transitando por un desierto en busca de agua. Los colores empleados enfatizan el contraste de ambos mundos, uno abundante, azul y verde y otro con escasez de agua representado en el amarillo de la tierra agrietada por la escasez de lluvias y el sol, que ha secado un árbol sin hojas que se halla inmerso en un tórrido mar rojo.

Otro pabellón desaparecido es el de "Ciudades del Agua" del arquitecto italiano Italo Rota, para el que Eboy (formado por Kai Vermehr, Steffen Sauerteig y Svend Smital) realizaron un mural de teselas de gres vidriadas llamado Enjoy your waterfront. Una vez terminada la muestra y remodelado el Frente Fluvial en 2009 el mural se instala de nuevo anclado sobre unas bases a modo de pilotis en un estanque de agua. Junto a él, uno de los árboles de chapa de acero diseñados por el propio arquitecto para el pabellón. Originalmente el mural se presentaba de forma continua pero en su nueva ubicación deciden dividirlo en dos mitades iguales, formando ángulo recto, con lo que se pierde la continuidad en la lectura de las imágenes. Los murales de Eboy se caracterizan por estar diseñados siguiendo el patrón ortogonal de los azulejos, lo que origina un diseño a modo de píxeles y otorga a las imágenes una cierta "arcaicidad" cercana a los gráficos de los videojuegos de los noventa. 
Su inspiración la encontramos en la cultura japonesa tradicional, presente en la icónica Gran ola de Kanagawa de Hokusai, y en la cultura contemporánea audiovisual expresada en la multiplicidad de escenas, en la superposición de imágenes y en el uso de un rico colorido en el que predomina el azul del agua, tema en torno al que giró la Expo Zaragoza 2008.

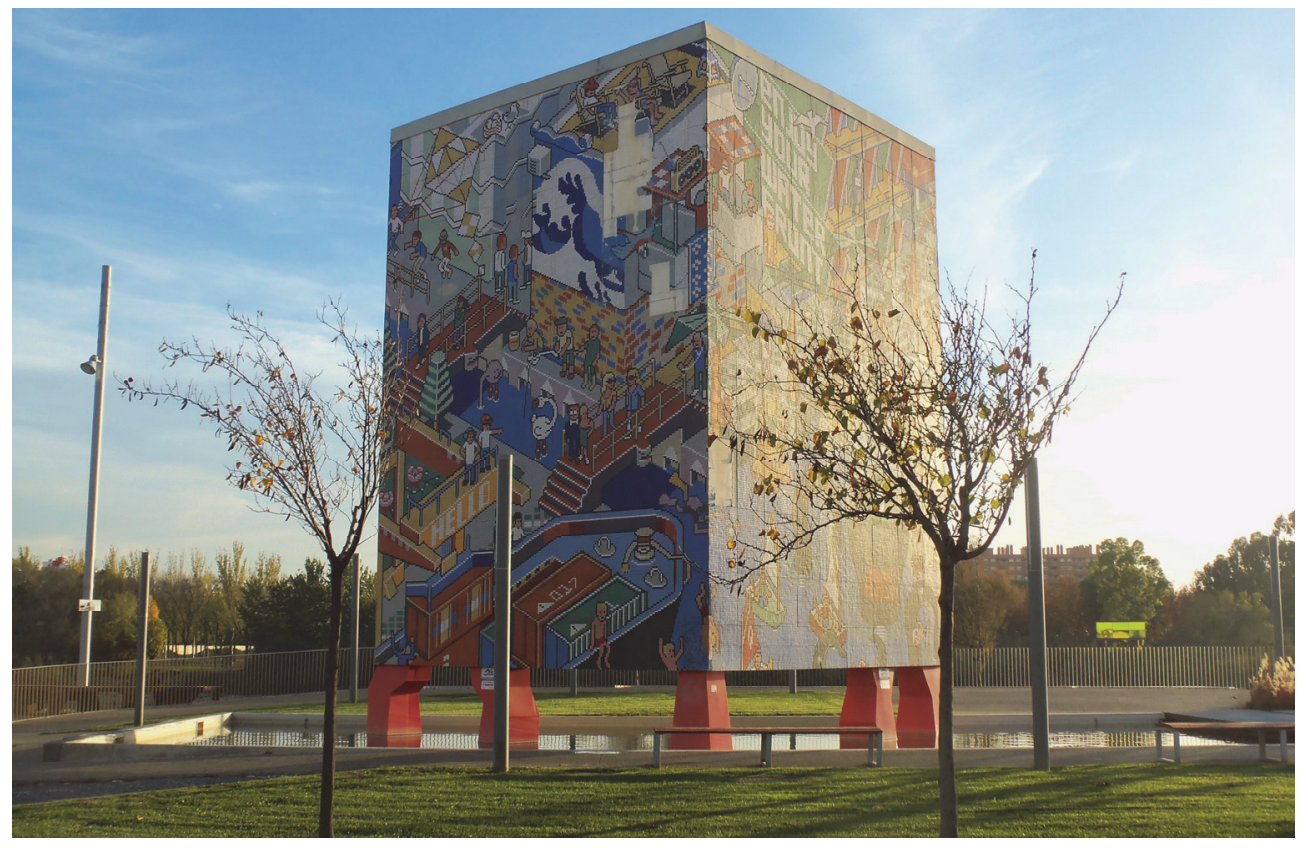

Fig. 10. Eboy, Enjoy your waterfront, Frente fluvial, Zaragoza. Fuente: S. Arilla

\section{Bibliografía}

AA.VV. (1998): Un mural para Aragón. Antonio Saura-Fidel Ferrando. Sala de Exposiciones del Ayuntamiento de Alcañiz. 27 de marzo - 26 de abril.

ANÓNIMO (1941): "Arquitectura popular española. Detalles decorativos". Reconstrucción. Madrid, no 13, pp. 26-34.

ANÓNIMO (1987): “Cerámica y Ceramistas”. Cerámica. Madrid, no 26, pp. 13-15.

ANÓNIMO (1953): “La Clínica San Juan de Dios". Labor Hospitalaria. Barcelona, año VI, no 31, pp. 179-193.

ANÓNIMO (1982): “Eduardo Cuní". Cerámica. Madrid, nº 13, pp. 30-35.

AlFONSO, Eduardo (1970): Cuní, Barcelona. 
AlmeríA, José A.; GimÉneZ, Cristina; LOMBA, Concha y RÁBAnOS, Carmen (1983): "El patrimonio artístico de la Universidad de Zaragoza", en AA.VV. Historia de la Universidad de Zaragoza. Editora Nacional, Madrid, pp. 435-478.

ARA FernándeZ, Ana (2007): Ceramistas de la Plaza San Felipe. 25 años. Zaragoza, Torreón Fortea, 4-23 septiembre.

ARA FERNÁNDEZ, Ana (2008): “Conclusiones sobre la producción en los últimos años 60 de un caso concreto: la ciudad de Zaragoza". On the w@terfron. Barcelona, no 11, pp. 109-117.

ARILla SATUÉ, Sonia (2015): "El mundo cerámico de Eduardo Alfonso Cuní", en Chaves Martín, Miguel Angel (Dir.). Artes Plásticas y ciudad. Grupo de Investigación Arte, Arquitectura, y Comunicación en la Ciudad Contemporánea. Universidad Complutense de Madrid, Madrid, pp. 63-70.

ARILLA SATUÉ, Sonia (2012): “Los murales cerámicos de Galdeano en la esfera pública". II Congreso de la AECC. La Rambla (Córdoba), 28-29 de septiembre.

ARILla SATUÉ, Sonia (2013): "Murales cerámicos en el espacio público zaragozano", en Diego, Lourdes y Lorente, Jesús-Pedro (coord.), Arte en las ciudades, las ciudades en el arte. Ediciones Universidad San Jorge, Zaragoza, pp. 127-138.

ARILLA SATUÉ, Sonia (2014): “La cerámica en la obra arquitectónica de Santiago Lagunas", en AA.VV. Santiago Lagunas. Vuelo alto y profundo. Palacio de Sástago, Zaragoza, del 3 de octubre de 2013 al 5 de enero de 2014, pp. 15-25.

AZPEITIA, Angel (1966): “Cuní o la investigación en cerámica”. Heraldo de Aragón. Zaragoza, 6 de marzo, p, 5.

BLASCO, A. y SÁNCHEZ, J. L. (1962): “La cerámica y la arquitectura". Arquitectura. Madrid, no 41 , pp. 38-40.

BORRÁs GUALIS, Gonzalo M. (1997): “Los elementos decorativos en la arquitectura de Santiago Lagunas: a propósito de los azulejos para la Clínica de San Juan de Dios de Zaragoza (1946-1953)", en AA.VV. Santiago Lagunas. Espacio y color. Museo Camón Aznar y Colegio Oficial de Arquitectos de Aragón, Zaragoza, del 17 de abril al 1 de junio de 1997, pp. 37-40.

CATÁlogo on-line de arte público del Ayuntamiento de Zaragoza: $<$ www.zaragoza.es/artepublico > (consultado: 10-11-2015).

CIRICI, Alexander (1977): La estética del franquismo. Gustavo Gili. Barcelona. 
DurÁn LORIGA, M. y MARTITEguI, J. (1960): “Cerámicas”. Arquitectura. Madrid, no 14, pp. 34-38.

GARCíA GUATAS, Manuel (1991): “El Dorado, todo un sueño”, en AA.VV. Lagunas. Abstracción. La Lonja, Zaragoza, 1 de marzo a 10 de abril, 1991, pp. 19-25.

García GuATAs, Manuel y LoRenTe, Jesús Pedro (coords.) (2011): Arte público en la ciudad de Zaragoza. Ayuntamiento de Zaragoza. Zaragoza.

GonZAlvo, María (2010): “El Parque de la Granja está recién reformado. Lo importante es que dure". Heraldo de Aragón. Zaragoza, 18 de junio.

GuILLÉN, Silvia (2008): “Jardín de la Memoria y Parque Oliver de Zaragoza: dos ejemplos de producción y gestión ciudadana del espacio público". On the w@terfront. Barcelona, no 11, pp. 163-172.

LORENTE, Jesús Pedro (2008): El escultor Ángel Orensanz. Un artista global en la esfera pública. Editorial Aqua-Orensanz Foundation-CerPolis. ZaragozaNueva York-Barcelona.

PéReZ-LiZANO, M. (1994): Abstracción Plástica Española. Núcleo Aragonés: 19481993. Mira Editores. Zaragoza.

RIVERO, José (2005): “Colonización: Figuración. Abstracción y vacío”. PH. Boletín del Instituto Andaluz de Patrimonio Histórico. Sevilla, no 52, febrero 2005, pp. 78-87.

SEMPERE, Emili (2008): "25 anys Ceramistas de la Plaza San Felipe". Terrart. Barcelona, no 32, pp. 36-38.

UREÑA, Gabriel (1982): Las vanguardias artísticas en la posguerra española. 19401959. Itsmo. Madrid.

VAlteCSA (2000): Inventario de los monumentos en la vía pública. Ayuntamiento de Zaragoza. Zaragoza.

YESTE, Isabel (2009): “Del centenario de los sitios a la Exposición Internacional 2008", en AA.VV. La ciudad de Zaragoza 1908-2008. Actas del XIII Coloquio de Arte Aragonés. Zaragoza, pp. 11-62.

Zapater, A. (1967): “Cuní: busco la calidad de la piedra”. Heraldo de Aragón. Zaragoza, 4 de junio, p. 5.

ZAPATER, A. (1971): “Galdeano, de pintor a ceramista, especializado en murales gigantescos". Heraldo de Aragón. Zaragoza. 17 de noviembre, p. 5. 